\title{
Characterization of Antibiotics and Antibiotic Resistance Genes on an Ecological Farm System
}

\author{
Songhe Zhang, ${ }^{1,2}$ Ju Gu, ${ }^{1}$ Chao Wang, ${ }^{1}$ Peifang Wang, ${ }^{1}$ Shaojun Jiao, \\ ZhenLi He, ${ }^{2}$ and Bing $\mathrm{Han}^{3}$ \\ ${ }^{1}$ Integrated Regulation and Resource Development on Shallow Lakes of Ministry of Education, College of Environment, \\ Hohai University, Nanjing 210098, China \\ ${ }^{2}$ Nanjing Institute of Environmental Science, Ministry of Environmental Protection of China, Nanjing, Jiangsu 210042, China \\ ${ }^{3}$ Institute of Food and Agricultural Sciences, Indian River Research and Education Center (IRREC), University of Florida, \\ 2199 South Rock Road, Fort Pierce, FL 34945, USA
}

Correspondence should be addressed to Songhe Zhang; shzhang@hhu.edu.cn and Peifang Wang; pfwang2005@hhu.edu.cn

Received 11 December 2014; Accepted 15 March 2015

Academic Editor: Athanasios Katsoyiannis

Copyright ( 2015 Songhe Zhang et al. This is an open access article distributed under the Creative Commons Attribution License, which permits unrestricted use, distribution, and reproduction in any medium, provided the original work is properly cited.

There is a growing concern worldwide about the prevalence of antibiotics and antibiotic resistance genes (ARGs) on the farm. In this study, we investigated the distribution of seven antibiotics and ten ARGs in fresh and dried pig feces, in biogas slurry, and in grapeplanting soil from an ecological farm. Antibiotics including sulfamethazine, norfloxacin, ofloxacin, tetracycline, oxytetracycline, and chlortetracycline were detected in these samples (except for sulfamethoxazole) in dried feces. In general, antibiotics levels in samples were in the sequence: biogas slurry $>$ fresh feces $>$ soil or dried feces. Results of ecological risk assessments revealed that among the seven antibiotics chlortetracycline showed the highest ecological risk. Among the ten ARGs, sulI and tet $\mathrm{O}$ were the most prevalent on this ecological farm. There were positive correlations between certain ARGs and the corresponding antibiotics on this ecological farm. Therefore, continuous monitoring of antibiotics and their corresponding ARGs should be conducted in the agroecosystem near the concentrated animal farming operation systems.

\section{Introduction}

Antibiotics have been extensively used in livestock to treat infections and to promote animal growth and feed efficiency. It has been estimated that approximately $30 \%$ of these antibiotics are metabolized in the bodies of animals [1]. Accompanying animal feces and urine, the majority of antibiotics and metabolites are released into environment [2]. At subtoxic levels, these antibiotics can lead to an increase in antibiotic resistant bacteria in the receiving environment [3] exerted by selection pressures on bacterial communities and, consequently, accelerating their resistance [4]. Therefore, livestock manure treatment and storage facilities have been considered potential sources of antibiotic resistant bacteria and of antimicrobial resistance genes (ARGs) in environment [5].

Abundant antibiotics are produced in China, and most of these antibiotics have been used in agriculture. It has been reported that over $8000 \mathrm{t}$ of antibiotics is used in livestock farm each year [6]. Meanwhile, abundant livestock manure wastes are generated each year. If these solid wastes have not been treated correctly, the residuals of antibiotics will be released and contaminate the soil and water. Currently, a higher level of antibiotic residues has been detected in agricultural land [7]. Manure application can also promote the spread of ARGs in soil $[8,9]$. Antibiotic resistant bacteria can spread numerous combinations of multiple resistance genes located on translocative elements (such as integrons and transposons), which can transmit ARGs into many species in soil and, subsequently, to other habitats. For example, a recent report showed that a smaller number of antibiotic resistance determinants were detected in bacterial community on vegetables grown in manured soil but not on vegetables grown in unmanured soil [10]. Consequently, the transfer of ARGs should be of concern in agriculture systems. However, the discharge routes for antibiotic resistance genes 
from farms to the environment have received much less attention and require further study [11].

There are approximately six million pigs in the Taihu Basin of China, and the excretion of animals in feedlots has been considered one of the pollution sources in this region. Therefore, in recent decades, farmers have been encouraged to build ecological farms where the wastewater and feces are recycled. To better understand the fate of antibiotics and ARGs on ecological farms, the present study was conducted to investigate the following concerns: (1) the fate and ecological risk of seven antibiotics (three tetracyclines (TCs), two sulfonamides (SAs), and two fluoroquinolones (FQs)); (2) the alterations of the ARGs in the ecological farm system using real-time PCR; and (3) the potential relations between antibiotics and their corresponding ARGs.

\section{Materials and Methods}

2.1. Sample Collection and Preparation. At least seven antibiotics (SMT: sulfamethazine; SMX: sulfamethoxazole; NFC: norfloxacin; OFC: ofloxacin; TET: tetracycline; OTC: oxytetracycline; CTC: chlortetracycline) were used as additives in the pig food at subtherapeutic levels for growth promotion and improvement of feed efficiency on an ecological farm in Yixing County, Jiangsu Province, China. On this ecological farm, fresh feces from a pig farm were dried, directly used as fertilizers, or fermented for biogas production, whereas biogas slurries were further used as a fertilizer for grapes.

All samples were collected three times (one time per week) at the same sites in the dry season (March 2013). For sample time, $1 \mathrm{~kg}$ of mixed fresh or dried feces (from at least 30 pigs of approximately forty $\mathrm{kg}$ ), $1 \mathrm{~L}$ of fresh biogas slurry, and $500 \mathrm{~g}$ of surface soil samples were collected. To obtain the mean level of the parameters in soil, the soil samples were selected from sites located in the center, middle, and edges of the grape garden using sterile spades and then mixed for each replicate in the lab. These samples were stored in an icebox and transported to the lab within $6 \mathrm{~h}$. In the lab, pig biogas slurry was filtered through a $0.22 \mathrm{~mm}$ glass fiber filter, and then the solid and the liquid phases were immediately separated. All of the solid materials were freeze-dried and ground into fine powder for further analysis.

2.2. Extraction and Determination of Antibiotics. $100 \mathrm{~mL}$ of filtered pig biogas slurry was collected, and its $\mathrm{pH}$ value was adjusted to 3.0 by using $3.0 \mathrm{M} \mathrm{H}_{2} \mathrm{SO}_{4}$ before $0.25 \mathrm{~g}$ $\mathrm{Na}_{2}$ EDTA was added. The extraction of antibiotics was performed according to the methods described by Xu et al. [13], with modification. Briefly, $100 \mathrm{ng}$ of ${ }^{13} \mathrm{C} 3$-caffeine was added to each sample as a surrogate before extraction. An Oasis HLB cartridge $(6 \mathrm{~mL}, 500 \mathrm{mg}$ ) (Waters Corporation, Milford, USA) used for the solid-phase extraction (SPE) was sequentially preconditioned with $8.0 \mathrm{~mL}$ of methanol, $8.0 \mathrm{~mL}$ of ultrapure water, and $8.0 \mathrm{~mL}$ of $10 \mathrm{mmol} / \mathrm{L} \mathrm{Na}_{2}$ EDTA buffer $(\mathrm{pH} 3.0)$ at a flow rate of approximately $3 \mathrm{~mL} / \mathrm{min}$. All of the samples were passed through the SPE columns at a flow rate of approximately $10 \mathrm{~mL} / \mathrm{min}$. Then, the HLB column was rinsed with $10 \mathrm{~mL}$ of ultrapure water $(\mathrm{pH} 3.0)$ and dried under nitrogen gas for approximately $30 \mathrm{~min}$. After drying, each cartridge was eluted with $8 \mathrm{~mL}$ of methanol at a flow rate of $1 \mathrm{~mL} / \mathrm{min}$. The analytes were collected into a $10 \mathrm{~mL}$ brown glass vial. After the volume of analytes was reduced to approximately $0.5 \mathrm{~mL}$ under nitrogen purge, methanol was added to a final volume of $1.0 \mathrm{~mL}$.

Antibiotic extraction from pig feces, the freeze-dried biogas slurry, or the grape-planting soil was performed according to the report by Li et al. [12]. Briefly, $200 \mathrm{ng}{ }^{13} \mathrm{C} 3$-caffeine (surrogate) and $1.0 \mathrm{~g}$ of solid samples were well mixed in $10 \mathrm{~mL}$ extraction buffer (a mixture of methanol and EDTAMcIlvaine at $1: 1(\mathrm{v} / \mathrm{v}))$ in $50 \mathrm{~mL}$ polypropylene centrifuge tubes. After vortex mixing for $1 \mathrm{~min}$, the mixtures were placed in an ultrasonic bath for $15 \mathrm{~min}$ (water temperature $40^{\circ} \mathrm{C}$ ) and were then centrifuged for $10 \mathrm{~min}$ at $3000 \mathrm{~g}$. The supernatant solution was decanted into a $500 \mathrm{~mL}$ glass bottle, and the solid residue was extracted twice. The supernatant solutions were combined and diluted to approximately $500 \mathrm{~mL}$ with ultrapure water, with the $\mathrm{pH}$ adjusted to approximately 3.0 by using $3.0 \mathrm{M} \mathrm{H}_{2} \mathrm{SO}_{4}$. The subsequent extraction processes were the same as those processes for the water samples.

To determine the concentrations of antibiotics in the piggery and in the recipient soil, an optimized HLBUPLC/MS/MS method was applied for the determination of the antibiotic residues in environmental samples, including air-dried pig manure, fresh manure slurry, and soil (0$30 \mathrm{~cm}$ in depth). A BEH C18 $(100 \mathrm{~mm} \times 2.0 \mathrm{~mm}$ i.d $1.7 \mu \mathrm{m})$ chromatography column was employed and operated at $35^{\circ} \mathrm{C}$. Optimum separation was achieved using gradient elution. The mobile phase consisted of A (water with $0.1 \%$ (v/v) formic acid) and B (methanol). The gradient was set up as follows: $0-1 \mathrm{~min}$ linear gradient to $10 \% \mathrm{~B}, 2-7 \mathrm{~min}$ linear gradient to $60 \% \mathrm{~B}, 7-9 \mathrm{~min}$ linear gradient to $90 \% \mathrm{~B}$, and $8-10 \mathrm{~min}$ linear gradient to $100 \%$ and it was maintained at $100 \%$ for five minutes. The injection volume was $10 \mu \mathrm{L}$, and the flow rate was $0.45 \mathrm{~mL} / \mathrm{min}$. Mass spectrometric measurements were performed on a WATERS UPLC TQD (Waters, USA) equipped with an electrospray ionization source. The analysis was performed in the positive mode for the antibiotics. The temperature of the heated capillary was $290^{\circ} \mathrm{C}$, and the source voltage was set to $5.0 \mathrm{kV}$. Mass spectra of derivatives of antibiotics were identified by selected-ion monitoring (SIM); one characteristic fragment ion was monitored in addition to the molecular ion of each compound: $m / z 254,108$ (SMX); $m / z$ 279,186 (SMT); $m / z$ 320,302 (NFC); $m / z$ 362,302 (OFC); $m / z$ 445,410 (TC); $m / z 461,443$ (OTC); and $m / z$ 479,444 (CTC). The concentrations of these antibiotics were calculated according to the recovery rate.

2.3. Potential Risk Assessment of Antibiotics for Farm Application. Risks of these antibiotics on farm soil microorganisms were estimated according to the method described by Li et al. [12]. In brief, the potential concentrations of these antibiotics in the top $0-25 \mathrm{~cm}$ of farm soil were predicated based on the frequency and content of fecal and biogas slurry and of effluents from biogas plants in this garden. Normally, $35,000 \mathrm{~kg}$ fresh feces, 16,000 kg dried feces, 100,000 L biogas effluents, or $30,000 \mathrm{~kg}$ biogas slurry was applied to one hectare of 
TABLE 1: Concentrations of antibiotics in the solid phase $\left(\mu \mathrm{gg}^{-1}\right.$ dried weight) and in the aqueous phase of the biogas slurry $\left.(\mu \mathrm{g} \mathrm{L})^{-1}\right)\left(\mathrm{mean}^{ \pm}\right.$ $\mathrm{SE})$.

\begin{tabular}{|c|c|c|c|c|c|}
\hline \multirow{2}{*}{ Antibiotic } & \multirow{2}{*}{ Fresh feces } & \multirow{2}{*}{ Dried feces } & \multicolumn{2}{|c|}{ Biogas slurry } & \multirow{2}{*}{ Soil } \\
\hline & & & Aqueous phase & Solid phase & \\
\hline \multicolumn{6}{|l|}{ SAs } \\
\hline SMX & $0.44 \pm 0.21^{\mathrm{a}}$ & $\mathrm{BDL}$ & $5.30 \pm 0.72$ & $0.05 \pm 0.01^{\mathrm{b}}$ & $0.01 \pm 0.00^{\mathrm{b}}$ \\
\hline SMT & $0.45 \pm 0.17^{\mathrm{a}}$ & $0.08 \pm 0.01^{\mathrm{b}}$ & $1.83 \pm 0.23$ & $0.08 \pm 0.01^{\mathrm{b}}$ & $0.01 \pm 0.00^{\mathrm{b}}$ \\
\hline \multicolumn{6}{|l|}{ FQs } \\
\hline NFC & $0.63 \pm 0.19^{\mathrm{a}}$ & $0.20 \pm 0.07^{\mathrm{b}}$ & $3.48 \pm 0.77$ & $0.46 \pm 0.01^{\mathrm{a}}$ & $0.04 \pm 0.01^{\mathrm{b}}$ \\
\hline OFC & $0.79 \pm 0.11^{\mathrm{a}}$ & $0.15 \pm 0.02^{\mathrm{c}}$ & $2.63 \pm 0.35$ & $0.47 \pm 0.04^{\mathrm{b}}$ & $0.03 \pm 0.01^{\mathrm{c}}$ \\
\hline \multicolumn{6}{|l|}{ TCs } \\
\hline TC & $7.31 \pm 0.21^{\mathrm{b}}$ & $3.51 \pm 0.64^{c}$ & $25.40 \pm 0.51$ & $13.68 \pm 0.62^{\mathrm{a}}$ & $0.06 \pm 0.01^{\mathrm{d}}$ \\
\hline OTC & $0.95 \pm 0.21^{\mathrm{b}}$ & $0.28 \pm 0.08^{c}$ & $13.05 \pm 0.48$ & $4.25 \pm 0.43^{\mathrm{a}}$ & $0.02 \pm 0.00^{c}$ \\
\hline CTC & $285 \pm 0.21^{\mathrm{b}}$ & $57.42 \pm 4.74^{\mathrm{c}}$ & $271.83 \pm 6.91$ & $407.19 \pm 8.67^{\mathrm{a}}$ & $0.13 \pm 0.02^{\mathrm{d}}$ \\
\hline
\end{tabular}

BDL: below the detection limitation. The mean antibiotics concentration in solid sample followed by different letters indicates a significant difference at $P<$ 0.05 .

land. Therefore, the predicted environmental concentrations (PECs) of antibiotics in soil (in milligrams per kilogram) were calculated according to the method by Spaepen et al. [14] (1). The predicted no-effect concentrations (PNECs) of SMX, TC, OTC, and CTC in soil (in $\mathrm{mg} / \mathrm{kg}$ or $\mathrm{mg} / \mathrm{L}$ ) were cited from $\mathrm{Li}$ et al. [12]:

$$
\begin{gathered}
\text { PECs }=\frac{(M \times C)}{((100 \times D)+M)} ; \\
\mathrm{HQ}=\frac{\text { PECs }}{\text { PNECs }},
\end{gathered}
$$

where $M$ is the weight of biosolids applied on one hectare of farmland; $C$ is the current concentration of veterinary antibiotics in feces, biogas slurry, and effluents; and $D$ is the mass of the top $0-25 \mathrm{~cm}$ of soil on farmland (in kg per hectare). For this study, a soil depth of $25 \mathrm{~cm}$ with a density of $1.35 \mathrm{~g} \mathrm{~cm}^{-3}$ was used. Finally, the ecological risk of antibiotics to soil microorganisms was assessed by the value of a hazard quotient (HQ) (2) [15].

\subsection{DNA Extraction and Quantification of Antibiotic Resis-} tance Genes. Total DNA was extracted from the air-dried pig manure, the freeze-dried biogas slurry, or the grape-planting soil using a Fast DNA-Spin Kit for Soil (Bio-Rad, Carlsbad, CA, USA) in accordance with the manufacturer's protocol. DNA extracts were quantified using a NanoDrop spectrometer (ND-1000, Thermo Fischer Scientific, Wilmington DE, USA) and a serial dilution (1:50-500) of DNA extracts and primers of 16S rRNA gene (Table S1 in Supplementary Material available online at http://dx.doi.org/10.1155/2015/526143) was used to find the optimal concentration of DNA. Reactions were assembled in 48-well plates to a final volume of $20 \mathrm{~mL}$ using SYBR Green Super Mix (Bio-Rad, Carlsbad, CA, USA) including $1 \mu \mathrm{L} 5 \mathrm{nM}$ each primers, $10 \mu \mathrm{L}$ SYBR Green Super Mix and 1-4 $\mu \mathrm{L}$ diluted DNA. The primers, along with the annealing temperatures used for the antibiotic resistance genes and bacterial 16S rRNA genes, are listed in Table S1. qPCR reactions were performed with a program of $5 \mathrm{~min}$ at $95^{\circ} \mathrm{C}, 50$ cycles $\left(15 \mathrm{~s}\right.$ at $95^{\circ} \mathrm{C}, 30 \mathrm{~s}$ at the annealing temperature (Table S1), which was incorporated with a melting curve stage with temperature ramping from $55^{\circ} \mathrm{C}$ to $95^{\circ} \mathrm{C}$, and an extension step at $72^{\circ} \mathrm{C}$ for $30 \mathrm{~s}$ ). For the verification of correct product size, the PCR amplicons were stained with ethidium bromide and subjected to electrophoresis on $2 \%$ agarose gels.

The DNA of these target genes was amplified from ARBs and then was cloned into the pGEM-T Easy plasmids (Promega Corporation, Madison, WI, USA), which were transformed into E. coli strain TOP10 cells. 10-fold serial dilutions of plasmids ranging from $10^{8}$ to $10^{2}$ gene copies $/ \mu \mathrm{L}$ were used to construct qPCR standard curves of these genes. The $R^{2}$ values were more than 0.99 for all calibration curves. Samples were analyzed in triplicate with a standard curve, and a negative control was included in each run. Relative concentrations of ARGs (normalized to the 16S rRNA gene copy number) were calculated in each solid sample. Gene concentrations were quantified in triplicate within each assay.

2.5. Statistical Analysis. The data were expressed as the mean \pm standard errors $(n=3)$ for three sample times. Experimental data were analyzed by a one-way analysis of variance (ANOVA), which was followed by Duncan's post hoc analysis at $P<0.05$. Correlation between concentrations of antibiotics and corresponding ARGs in solid samples was analyzed $(n=12)$. All statistical analyses were performed with SPSS software (version 19.0).

\section{Results and Discussion}

3.1. Concentration of Antibiotics in Pig Manure, Biogas Slurry, and Soil Samples. Significant differences in the concentrations of the seven antibiotics were observed among the dried manure, biogas slurry, and soil amended with pig manure (Table 1). Similar levels of antibiotics were also detected in pig feces from six typical pig farms in southern China [16]. The antibiotic residues in manure may be from food as additives or from antibiotic injections $[17,18]$. In fact, all of these antibiotics were detected in the feed (data not shown). 
TABLE 2: Potential risk values (HQ) of antibiotics on the soil bacterial community.

\begin{tabular}{lcccccc}
\hline \multirow{2}{*}{ Antibiotics } & PNECs $^{\mathrm{a}}$ & \multicolumn{2}{c}{ Feces } & \multicolumn{2}{c}{ Biogas slurry } \\
& $\left(\mu \mathrm{g} \mathrm{kg}^{-1}\right)$ & Fresh & Dried & Effluent & Solid \\
\hline SMX & 270 & $1.69 E-3$ & $\backslash$ & $5.82 E-2$ & $1.65 E-4$ & $3.70 E-2$ \\
TC & 270 & $2.81 E-2$ & $6.16 E-3$ & $2.79 E-1$ & $4.50 E-2$ & $2.22 E-1$ \\
OTC & 50 & $1.97 E-2$ & $2.65 E-3$ & $7.73 E-1$ & $7.56 E-2$ & $4.00 E-1$ \\
CTC & 53 & 5.58 & 0.51 & 15.20 & 6.83 \\
\hline
\end{tabular}

${ }^{a}$ PNECs were used as described by Li et al. (2013) [12].

These data demonstrated that livestock farms are considered an important pollution source of various antibiotics to the receiving environments [19]. The concentrations of the TC class were obviously higher than that of SAs and FQs, and CTC was found at the highest concentration in every sample, followed by TC and by OTC (Table 2). A previous report showed that tetracycline concentration at range of $42-698 \mathrm{mg} \mathrm{L}^{-1}$ was detected in manure slurry of Danish farmland [20]. A recent report also showed that tetracyclines were predominant in pig feces and that sulfonamides were common, with the highest concentration $\left(7.11 \mathrm{mg} \mathrm{kg}^{-1}\right)$ in 18 fecal samples from a pig farm [12]. The concentrations of antibiotics were significantly higher in fresh feces than in dried feces (Table 1), suggesting that the antibiotics might be degraded or evaporated during the drying process under sunlight. Therefore, the drying process may be a better way to remove excess antibiotics in feces.

Feces and wastewaters from pig farms are used as raw materials in biogas production to prevent the pollution of surface water in China. However, the residues of antibiotics in the aqueous and solid phases in biogas slurry remain unclear. The concentrations of SAs were obviously higher in the aqueous phase than in the solid phase (Table 1), which may be ascribed to the weak adsorption and tendency of SAs to persist in aqueous samples $[21,22]$. FQs and TCs, including TC and OTC, were higher in the aqueous phase than in the solid phase, whereas CTCs had an opposite trend (Table 1). Gao et al. [23] demonstrated that the removal of TCs was primarily attributed to sorption onto sludge in the wastewater treatment plants. These differences may be ascribed to the adsorbents and antimicrobials, which have different physicochemical properties, such as molecular structure, size, shape, solubility, speciation, and hydrophobicity $[5,24]$. The high level of antibiotics in the biogas slurry (Table 1) suggests that not all of the antibiotics are biologically degraded under anaerobic fermentation conditions [25]. The residual antibiotics may have negative effects on biogas production [17].

The concentration of antibiotics in the manure-amended soil ranged from 0.02 to $0.12 \mu \mathrm{gg}^{-1}$. Concentrations of TCs were higher than any other antibiotics, indicating that the transfer from manure to the soil was responsible for their occurrence in the soil. The levels of SAs were lower than that of FQs and TCs in the soil (Table 1). Overall, the concentrations of antibiotics in the soil were much lower than those concentrations in the manure. Recently, Ji et al. [26] found the presence of sulfonamides and tetracyclines at concentration ranges of 3.27-17.85, 5.85-33.37, and 4.54$24.66 \mathrm{mg} \mathrm{kg}^{-1}$ in agricultural soils adjacent to feedlots in Shanghai, China. The antibiotics released to soils by the application of manure can be degraded or inactivated to various degrees through abiotic processes, such as adsorption onto soil components, loss to groundwater or to surface water through leaching or runoff, or being taken up by plants, depending on antibiotic species and on soil properties [24].

3.2. Potential Risk of Antibiotics to Microorganisms in the Soil. Although the concentrations of antibiotics were low in the soil, these concentrations can have an effect on the occurrence of ARGs in bacteria. Based on the quantities of fresh feces and dried feces and the aqueous phase of biogas slurry or the solid phase of biogas slurry applied on the grape soil, the PECs of seven antibiotics in the grape soil were calculated (Table S2). The PECs covered the detected concentrations in the soil (Table 1 and Table S2), except for NFC. The application of the aqueous phase of biogas slurry could clearly increase the concentrations of these antibiotics in the soil (Table S2). PECs of these antibiotics ranged from $3.79 E-5 \mu \mathrm{g} \mathrm{g}^{-1}$ soil for SMT (amended with dried feces) to $8.05 E-1 \mu \mathrm{gg}^{-1}$ soil for CTC (amended with the aqueous phase of biogas slurry), indicating that the PECs and concentrations of these antibiotics in this study overlapped with the EC50 at an ecological level for aquatic organisms that was reported by Sanderson et al. [27].

Because little data concerning the antibiotic toxicity (EC50) values for soil bacteria are available compared with those values for aquatic organisms [27, 28], the potential risks of four antibiotics to soil microorganisms were estimated according to the content of the biosolids or effluents manually applied to the soil (Table 2). If the value of the HQ is below 1 unit, then no ecological risks are expected; otherwise, potential ecological risks may be observed. As shown in Table 2, SMX displayed no environmental risks. SMX also had no ecological risks, although sulfonamide concentrations as low as $0.1 \mu \mathrm{gg}^{-1}$ soil could have a selective effect on resistant bacteria in the soil [18]. TC and OTC in fresh and dried feces and in biosolids from the biogas plant showed no environmental risks, whereas TC and OTC in the aqueous phase of the biogas slurry had high environmental risks. Among the four antibiotics, in all samples, CTC was estimated to have a HQ value above 1, except for dried feces, suggesting that the application of fresh feces, effluent, and solids from the biogas plant may result in an ecological risk to the soil 
TABLE 3: Relative concentrations of ARGs (normalized to copy numbers of $16 \mathrm{~s}$ rDNA) in solid samples (mean \pm SE).

\begin{tabular}{|c|c|c|c|c|}
\hline Sample & Fresh feces & Dried feces & Biogas slurry & Grape soil \\
\hline sulI $\left(\times \mathbf{1 0}^{-2}\right)$ & $2.2 \pm 0.00^{c}$ & $2.4 \pm 0.08^{c}$ & $5.83 \pm 5.44^{\mathrm{b}}$ & $39.19 \pm 0.77^{\mathrm{a}}$ \\
\hline sulII $\left(\times 10^{-3}\right)$ & $8.99 \pm 0.90^{\mathrm{a}}$ & $9.05 \pm 1.88^{\mathrm{a}}$ & $0.37 \pm 0.06^{\mathrm{b}}$ & $0.42 \pm 0.08^{\mathrm{b}}$ \\
\hline sulIII $\left(\times 10^{-3}\right)$ & $6.09 \pm 0.59^{\mathrm{a}}$ & $6.19 \pm 1.19^{\mathrm{a}}$ & $0.20 \pm 0.04^{\mathrm{b}}$ & $0.48 \pm 0.10^{\mathrm{b}}$ \\
\hline $\operatorname{sulA}\left(\times 10^{-3}\right)$ & $0.20 \pm 0.09^{b c}$ & $0.31 \pm 0.05^{\mathrm{b}}$ & $0.11 \pm 0.04^{\mathrm{c}}$ & $0.71 \pm 0.01^{\mathrm{a}}$ \\
\hline$q n r \mathrm{~A}\left(\times \mathbf{1 0}^{-3}\right)$ & $0.32 \pm 0.03^{\mathrm{a}}$ & $0.21 \pm 0.21^{\mathrm{b}}$ & $0.01 \pm 0.00^{c}$ & $\mathrm{BDL}$ \\
\hline$q n r S\left(\times 10^{-3}\right)$ & $0.12 \pm 0.01^{\mathrm{a}}$ & $0.04 \pm 0.00^{\mathrm{d}}$ & $0.05 \pm 0.00^{c}$ & $0.08 \pm 0.02^{\mathrm{b}}$ \\
\hline tet $\mathrm{A}\left(\times 10^{-3}\right)$ & $2.03 \pm 0.16^{\mathrm{a}}$ & $1.28 \pm 0.09^{\mathrm{b}}$ & $0.15 \pm 0.03^{c}$ & $0.02 \pm 0.00^{c}$ \\
\hline tet $\mathrm{E}\left(\times \mathbf{1 0}^{-3}\right)$ & $2.45 \pm 0.23^{\mathrm{b}}$ & $1.06 \pm 0.24^{\mathrm{b}}$ & $2.96 \pm 0.61^{\mathrm{a}}$ & $1.35 \pm 0.26^{\mathrm{b}}$ \\
\hline tet $\mathrm{B}\left(\times 10^{-3}\right)$ & $1.02 \pm 0.10^{\mathrm{b}}$ & $0.49 \pm 0.21^{\mathrm{c}}$ & $2.91 \pm 1.09^{\mathrm{a}}$ & $0.44 \pm 0.07^{\mathrm{c}}$ \\
\hline tet $\mathrm{O}\left(\times \mathbf{1 0}^{-2}\right)$ & $2.00 \pm 0.19^{c}$ & $1.67 \pm 0.27^{\mathfrak{c}}$ & $22.71 \pm 8.33^{\mathrm{a}}$ & $10.55 \pm 1.23^{b}$ \\
\hline
\end{tabular}

BDL: below the detection limitation. The mean followed by different letters within the same row indicates a significant difference at $P<0.05$.

bacterial community. For soils amended with feces or with biogas slurry, OTC and CTC showed higher ecological risks than SMX and TC, implying that the application of manure might contribute to the increase of residual antibiotics in the soil (Table 2). Similarly, Li et al. [12] found that OTC and CTC were predominant in pig feces and displayed ecological risks. These results suggest that the antibiotics in effluents always have higher risk potentials than those antibiotics in biosolids.

The availability of these antibiotics can be affected by various factors, such as soil types, $\mathrm{pH}$, water content, soil particle adsorption, climate, microbial population, and other pollutants in soils [12]. For instance, the antibiotics in soils can be degraded or be transported to groundwater and surface waters after rainfall and irrigation events on farm [2931]. However, the attenuation rate and leaching properties varied among different antibiotics. TCs and fluoroquinolones always have large sorption coefficient and can bind strongly to the soil matrix and thus persist longer in the soil environment than sulfonamides $[29,32]$. It should be noted that in the farm biogas slurry and swine feces were always applied to soil in dry (winter-spring) season in this region, and meanwhile, the effluents of biogas slurry were frequently used to irrigate the farmland. A recent report showed that average halflife of SMT in agricultural soils was 18.6 days [33], while, typically, generation times of bacteria range from 20 minutes to 20 hours depending on the bacterial species/strain and the conditions during which log-phase growth is occurring. Considering the complicated factors, the results in this study using conservative assumptions did not represent that there is a risk for acute toxic effects in the environment based on today's use of pharmaceuticals in this farm, but the results do not exclude the potential for chronic environmental effects [34]. Therefore, the authors suggest that extensive investigations should be performed to study the effects of pharmaceuticals on soil microorganisms or on terrestrial plants in the future.

3.3. Abundance of ARGs. Ten ARGs were detected and they showed significant differences in concentration among these samples (Table 3). The concentration of sulI was lower in fresh feces than in biogas slurry or in grape soil, whereas concentrations of sulII and sulIII were lower in biogas slurry or in grape soil than in fresh and dried feces. sulI is frequently detected in integron I, which is a kind of genetic elements that integrate or excise mobile cassette genes and can exist in manured soil for a long time [35]. The repeated application of manure may contribute to the accumulation of sul and integron I in farm soil $[2,35]$. The sulfonamide-resistant bacteria and sulgenes were detected in the sample sites located in the same region and the results showed that the sample type, animal type, and sampling time can influence the prevalence and distribution pattern of sulfonamide resistance genes [36]. The highest concentration of sulA was found in the grape soil sample, followed by dried feces, fresh feces, and biogas slurry. The genes sulI, sulII, sulIII, and sulA, which encode proteins that confer resistance to sulfonamides, have frequently been detected in surface water, in agricultural soils, and in livestock lagoons $[18,36,37]$. The abundance of sul in feces was greater in this study than that reported from other regions, such as Germany [18] and USA [38], reflecting the fact that SAs are used in an improper way at least on this farm.

Quinolones, which are among the most commonly prescribed antimicrobials in the world, are broad-spectrum drugs that appear to act by inhibiting the normal functions of bacterial type II topoisomerases, whereas the $q n r$ genes confer resistance to quinolone [37]. In the present study, $q n r S$ and $q n r \mathrm{~A}$ were detected in all of the solid samples, and their concentrations were obviously higher in feces than other samples. Although it has been reported that fermentation was ineffective in removing antibiotic resistant bacteria [39], the level of several ARGs was lower in biogas slurry than in fresh or dried feces (Table 3 ).

In this study, the relative abundance of tet genes in the swine manure ranged from $10^{-3}$ to $10^{-1}$, which is similar to that in swine and cattle manure in south China [5] but is higher than that in the cattle manure [38]. Among the four tet genes, the levels of tet $\mathrm{A}$ and tet $\mathrm{E}$ were always significantly higher in fresh feces than in dried feces, in biogas slurry, and in grape soil. The tet $\mathrm{B}$ concentration in fresh feces was lower than that in biogas slurry but higher than that in dried feces or in grape soil (Table 3). A significant increase in the tet $\mathrm{O}$ level was found in biogas slurry or in grape soil compared with that in fresh feces. In terms of tetracycline resistance genes, the relative abundance of tet $\mathrm{O}$ was much higher (more 
TABLE 4: Correlation between antibiotics and ARGs $(R)$ in an ecological farm system.

\begin{tabular}{lccccccc}
\hline ARGs & TC & OTC & CTC & SMX & SMT & NFC & OFC \\
\hline sulI & $/$ & $/$ & $/$ & -0.37 & -0.50 & $/$ & $/$ \\
sulII & $/$ & $/$ & $/$ & 0.50 & $0.61^{*}$ & $/$ & $/$ \\
sulIII & $/$ & $/$ & $/$ & 0.49 & $0.60^{*}$ & $/$ & $/$ \\
sulA & $/$ & $/$ & $/$ & -0.27 & -0.36 & $/$ & $/$ \\
$q n r \mathrm{~A}$ & $/$ & $/$ & $/$ & $/$ & $/$ & 0.53 & 0.57 \\
qnrS & $/$ & $/$ & $/$ & $/$ & $/$ & 0.48 & $0.62^{*}$ \\
tet $\mathrm{A}$ & 0.01 & -0.32 & 0.11 & $/$ & $/$ & $/$ & $/$ \\
tet $\mathrm{E}$ & $0.81^{*}$ & $0.92^{*}$ & $0.72^{*}$ & 1 & $/$ & $/$ & $/$ \\
tet $\mathrm{B}$ & $0.88^{*}$ & $0.95^{*}$ & $0.82^{*}$ & $/$ & $/$ & $/$ & $/$ \\
tet $\mathrm{O}$ & $0.58^{*}$ & $0.81^{*}$ & 0.50 & $/$ & & $/$ & $/$ \\
\hline
\end{tabular}

* Correction at a significant level of $P<0.05$.

than seven times) than the other three genes (tet $\mathrm{A}$, tet $\mathrm{B}$, and tet $\mathrm{E}$ ) in grape soil. Schwaiger et al. [40] also reported that the tet $\mathrm{O}$ genes showed higher concentrations when TC residues were detectable. Pakpour et al. [41] demonstrated that the abundance of tet $\mathrm{O}$ remained at high levels throughout the lifetime of the pigs. The levels of tet $\mathrm{E}$, tet $\mathrm{B}$, and tet $\mathrm{O}$ were higher in biogas slurry than in feces (Table 3). Recently, Barkovskii et al. [11] showed that transient ARG abundances were attenuated in lagoons to levels below the detection limit, whereas the persistent ARG abundances were 1001000 -fold amplified in their (mostly) liquid phases. These authors suggested that the major routes for the accumulation of ARGs in the soil might be manure irrigation, leakage, and spills from manure treatment lagoons and from the air plume. For example, the prevalence of sulfonamide-resistant isolates increased in a field soil after two years of slurry application of antibiotic-containing manure [42]. However, reports from Kyselková et al. [43] showed that application of oxytetracycline-rich and the oxytetracycline-free manure contributed equally to the increase of tetracycline resistome in soil and suggested that other mechanisms may be involved in the maintenance of TC-r genes in manured soils.

\subsection{Correlation between Concentrations of Antibiotics and} Corresponding ARGs. The relative concentrations of sulII and sulIII were significantly positively related to SMT (Table 4). A similar report showed that the accumulated SDZ exposure (until day 63) of the bacteria significantly correlated with the log relative abundance of sulI and of sulII [44]. Positive relations between $q n r S$ and OFC were also detected. Among the four tet genes, tet $\mathrm{E}$, tet $\mathrm{B}$, and tet $\mathrm{O}$ showed positive relations to at least two types of TETs (Table 4). Links between the occurrence of several antimicrobials and increasing antimicrobial resistance in the environment have been documented [45-47]. Recently, Liu et al. [48] found a weak positive correlation between ARGs and their corresponding antibiotics in the vertical flow constructed wetlands. These data demonstrate that residual antibiotics promoted the development of antibiotic resistance.

However, there were no obvious correlations between several antimicrobials and ARGs (Table 4), for example, the tet A to TETs and qnrA to FQs. Gao et al. [23] reported similar results in a wastewater treatment plant (WWPT) and showed that the absolute abundance of tet $\mathrm{O}$ and tet $\mathrm{W}$ showed no significant correlation with the total tetracycline (i.e., oxytetracycline, doxycycline, chlortetracycline, and tetracycline) concentration. A previous report showed that the manure amendment of agricultural soils typically added a considerable amount of bacteria harboring ARGs, even if the producing animals have never been treated with antibiotics [9]. Recently, Rahube and Yost [49] also found that many multiple antibiotic resistance plasmids could be detected in liquid pig manure that was applied to soil. Other important factors, such as heavy metals in the manure, may result in the coselection and cross selection of antibiotic resistance and, thus, affect the correlations [47]. Additionally, the attenuation rate of antibiotics and ARGs may be another possible reason [30, 31]. In fact, the abundances of ARGs are increasing because of the mass production and use of antimicrobials in medicine and in agriculture [50]. A recent report characterized the sulfonamide-resistant bacteria and their resistance genes in soils fertilized with manures from Jiangsu Province and highlighted the necessity and urgency of the regulation and supervision of veterinary antibiotics in China [51].

\section{Conclusions}

Seven antibiotics were detected in the fresh and dried feces, in the aqueous and solid phases of the biogas slurry, and in the grape-planting soil, except for SMX in dried feces. The antibiotics were primarily present in the aqueous phase of biogas slurry. Our results highlighted that antibiotics and corresponding ARGs in biogas production introduce a great challenge for the commercialization of biogas energy in China and internationally. OTC and CTC may have potential risks to the soil amended with the biogas slurry. Based on their relative concentrations, of the 10 ARGs, sulI and tetO were prevalent in the ecological farm. Several ARGs positively correlated with their corresponding antibiotics, suggesting that the spread of ARGs may be partially ascribed to the usage of antibiotics on the ecological farm. Though we only detected the presentence of antibiotics and ARGs in one season, the data well documented that the pig feedlots 
contribute to the spread of antibiotics and antibiotic resistance genes on an ecological farm. However, a long-term investigation should be conducted in samples from various types of ecological farms in the future.

\section{Conflict of Interests}

The authors declare that there is no conflict of interests regarding the publication of this paper.

\section{Acknowledgments}

This study was supported in part by grants from the Jiangsu Natural Science Foundation (nos. BK2012413 and BK2011082), the National Natural Science Foundation of China (nos. 51379063 and 21102053), and the National Natural Science Funds for Distinguished Young Scholar (no. 51225901).

\section{References}

[1] F. C. Cabello, "Heavy use of prophylactic antibiotics in aquaculture: a growing problem for human and animal health and for the environment," Environmental Microbiology, vol. 8, no. 7, pp. 1137-1144, 2006.

[2] H. Heuer, H. Schmitt, and K. Smalla, "Antibiotic resistance gene spread due to manure application on agricultural fields," Current Opinion in Microbiology, vol. 14, no. 3, pp. 236-243, 2011.

[3] T. Christian, R. J. Schneider, H. A. Färber, D. Skutlarek, M. T. Meyer, and H. E. Goldbach, "Determination of antibiotic residues in manure, soil, and surface waters," Acta Hydrochimica et Hydrobiologica, vol. 31, no. 1, pp. 36-44, 2003.

[4] C. R. Jackson, P. J. Fedorka-Cray, J. B. Barrett, and S. R. Ladely, "Effects of tylosin use on erythromycin resistance in enterococci isolated from swine," Applied and Environmental Microbiology, vol. 70, no. 7, pp. 4205-4210, 2004.

[5] Y. Zhang, C. Zhang, D. B. Parker, D. D. Snow, Z. Zhou, and X. $\mathrm{Li}$, "Occurrence of antimicrobials and antimicrobial resistance genes in beef cattle storage ponds and swine treatment lagoons," Science of the Total Environment, vol. 463-464, pp. 631-638, 2013.

[6] W. Ben, Z. Qiang, C. Adams, H. Zhang, and L. Chen, "Simultaneous determination of sulfonamides, tetracyclines and tiamulin in swine wastewater by solid-phase extraction and liquid chromatography-mass spectrometry," Journal of Chromatography A, vol. 1202, no. 2, pp. 173-180, 2008.

[7] X. Hu, Q. Zhou, and Y. Luo, "Occurrence and source analysis of typical veterinary antibiotics in manure, soil, vegetables and groundwater from organic vegetable bases, northern China," Environmental Pollution, vol. 158, no. 9, pp. 2992-2998, 2010.

[8] A. Götz and K. Smalla, "Manure enhances plasmid mobilization and survival of Pseudomonas putida introduced into field soil," Applied and Environmental Microbiology, vol. 63, no. 5, pp. 1980-1986, 1997.

[9] H. Heuer and K. Smalla, "Manure and sulfadiazine synergistically increased bacterial antibiotic resistance in soil over at least two months," Environmental Microbiology, vol. 9, no. 3, pp. 657666, 2007.

[10] R. Marti, A. Scott, Y.-C. Tien et al., "Impact of manure fertilization on the abundance of antibiotic-resistant bacteria and frequency of detection of antibiotic resistance genes in soil and on vegetables at harvest," Applied and Environmental Microbiology, vol. 79, no. 18, pp. 5701-5709, 2013.

[11] A. L. Barkovskii, K. M. Manoylov, and C. Bridges, "Positive and negative selection towards tetracycline resistance genes in manure treatment lagoons," Journal of Applied Microbiology, vol. 112, no. 5, pp. 907-919, 2012.

[12] Y.-X. Li, X.-L. Zhang, W. Li, X.-F. Lu, B. Liu, and J. Wang, "The residues and environmental risks of multiple veterinary antibiotics in animal faeces," Environmental Monitoring and Assessment, vol. 185, no. 3, pp. 2211-2220, 2013.

[13] W. Xu, G. Zhang, X. Li et al., "Occurrence and elimination of antibiotics at four sewage treatment plants in the Pearl River Delta (PRD), South China," Water Research, vol. 41, no. 19, pp. 4526-4534, 2007.

[14] K. R. I. Spaepen, L. J. J. van Leemput, P. G. Wislocki, and C. Verschueren, "A uniform procedure to estimate the predicted environmental concentration of the residues of veterinary medicines in soil," Environmental Toxicology and Chemistry, vol. 16, no. 9, pp. 1977-1982, 1997.

[15] S. Park and K. Choi, "Hazard assessment of commonly used agricultural antibiotics on aquatic ecosystems," Ecotoxicology, vol. 17, no. 6, pp. 526-538, 2008.

[16] L. J. Zhou, G. G. Ying, S. Liu et al., "Excretion masses and environmental occurrence of antibiotics in typical swine and dairy cattle farms in China," Science of the Total Environment, vol. 444, pp. 183-195, 2013.

[17] B. Ince, H. Coban, G. Turker, E. Ertekin, and O. Ince, "Effect of oxytetracycline on biogas production and active microbial populations during batch anaerobic digestion of cow manure," Bioprocess and Biosystems Engineering, vol. 36, no. 5, pp. 541546, 2013.

[18] H. Heuer, A. Focks, M. Lamshöft, K. Smalla, M. Matthies, and M. Spiteller, "Fate of sulfadiazine administered to pigs and its quantitative effect on the dynamics of bacterial resistance genes in manure and manured soil," Soil Biology and Biochemistry, vol. 40, no. 7, pp. 1892-1900, 2008.

[19] M. Qiao, W. Chen, J. Su, B. Zhang, and C. Zhang, "Fate of tetracyclines in swine manure of three selected swine farms in China," Journal of Environmental Sciences, vol. 24, no. 6, pp. 1047-1052, 2012.

[20] G. Sengeløv, Y. Agersø, B. Halling-Sørensen, S. B. Baloda, J. S. Andersen, and L. B. Jensen, "Bacterial antibiotic resistance levels in Danish farmland as a result of treatment with pig manure slurry," Environment International, vol. 28, no. 7, pp. 587-595, 2003.

[21] A. Białk-Bielińska, J. Maszkowska, W. Mrozik et al., "Sulfadimethoxine and sulfaguanidine: their sorption potential on natural soils," Chemosphere, vol. 86, no. 10, pp. 1059-1065, 2012.

[22] L. Tong, P. Li, Y. X. Wang, and K. Zhu, "Analysis of veterinary antibiotic residues in swine wastewater and environmental water samples using optimized SPE-LC/MS/MS," Chemosphere, vol. 74, no. 8, pp. 1090-1097, 2009.

[23] P. Gao, M. Munir, and I. Xagoraraki, "Correlation of tetracycline and sulfonamide antibiotics with corresponding resistance genes and resistant bacteria in a conventional municipal wastewater treatment plant," Science of the Total Environment, vol. 421-422, pp. 173-183, 2012.

[24] A. K. Sarmah, M. T. Meyer, and A. B. A. Boxall, "A global perspective on the use, sales, exposure pathways, occurrence, fate and effects of veterinary antibiotics (VAs) in the environment," Chemosphere, vol. 65, no. 5, pp. 725-759, 2006. 
[25] C. G. Daughton and T. A. Ternes, "Pharmaceutical and personal care products in the environment: agents of subtle change?" Environmental Health Perspectives, vol. 107, supplement 6, pp. 907-938, 1999.

[26] X. Ji, Q. Shen, F. Liu et al., "Antibiotic resistance gene abundances associated with antibiotics and heavy metals in animal manures and agricultural soils adjacent to feedlots in Shanghai; China," Journal of Hazardous Materials, vol. 235-236, pp. 178185, 2012.

[27] H. Sanderson, D. J. Johnson, C. J. Wilson, R. A. Brain, and K. R. Solomon, "Probabilistic hazard assessment of environmentally occurring pharmaceuticals toxicity to fish, daphnids and algae by ECOSAR screening," Toxicology Letters, vol. 144, no. 3, pp. 383-395, 2003.

[28] R. A. Brain, H. Sanderson, P. K. Sibley, and K. R. Solomon, "Probabilistic ecological hazard assessment: evaluating pharmaceutical effects on aquatic higher plants as an example," Ecotoxicology and Environmental Safety, vol. 64, no. 2, pp. 128$135,2006$.

[29] M. Burkhardt, C. Stamm, C. Waul, H. Singer, and S. Müller, "Surface runoff and transport of sulfonamide antibiotics and tracers on manured grassland," Journal of Environmental Quality, vol. 34, no. 4, pp. 1363-1371, 2005.

[30] P. A. Blackwell, P. Kay, R. Ashauer, and A. B. A. Boxall, "Effects of agricultural conditions on the leaching behaviour of veterinary antibiotics in soils," Chemosphere, vol. 75, no. 1, pp. 13-19, 2009.

[31] N. Fahrenfeld, K. Knowlton, L. A. Krometis et al., "Effect of manure application on abundance of antibiotic resistance genes and their attenuation rates in soil: field-scale mass balance approach," Environmental Science \& Technology, vol. 48, no. 5, pp. 2643-2650, 2014.

[32] R. Reichel, I. Rosendahl, E. T. H. M. Peeters et al., "Effects of slurry from sulfadiazine-(SDZ) and difloxacin-(DIF) medicated pigs on the structural diversity of microorganisms in bulk and rhizosphere soil," Soil Biology and Biochemistry, vol. 62, pp. 8291, 2013.

[33] C. Accinelli, W. C. Koskinen, J. M. Becker, and M. J. Sadowsky, "Environmental fate of two sulfonamide antimicrobial agents in soil," Journal of Agricultural and Food Chemistry, vol. 55, no. 7, pp. 2677-2682, 2007.

[34] Y.-J. Lee, S.-E. Lee, D. S. Lee, and Y.-H. Kim, "Risk assessment of human antibiotics in Korean aquatic environment," Environmental Toxicology and Pharmacology, vol. 26, no. 2, pp. 216-221, 2008.

[35] K. G. Byrne-Bailey, W. H. Gaze, L. Zhang et al., "Integron prevalence and diversity in manured soil," Applied and Environmental Microbiology, vol. 77, no. 2, pp. 684-687, 2011.

[36] N. Wang, X. Yang, S. Jiao, J. Zhang, B. Ye, and S. Gao, "Sulfonamide-resistant bacteria and their resistance genes in soils fertilized with manures from Jiangsu Province, Southeastern China," PLoS ONE, vol. 9, no. 11, Article ID el12626, 2014.

[37] C. Wang, X. Gu, S. Zhang et al., "Characterization of antibioticresistance genes in antibiotic resistance Escherichia coli isolates from a lake," Archives of Environmental Contamination and Toxicology, vol. 65, no. 4, pp. 635-641, 2013.

[38] M. Munir and I. Xagoraraki, "Levels of antibiotic resistance genes in manure, biosolids, and fertilized soil," Journal of Environmental Quality, vol. 40, no. 1, pp. 248-255, 2011.

[39] I. Han, S. Congeevaram, and J. Park, "Improved control of multiple-antibiotic-resistance-related microbial risk in swine manure wastes by autothermal thermophilic aerobic digestion," Water Science and Technology, vol. 59, no. 2, pp. 267-271, 2009.
[40] K. Schwaiger, K. Harms, C. Hölzel, K. Meyer, M. Karl, and J. Bauer, "Tetracycline in liquid manure selects for co-occurrence of the resistance genes tet $(\mathrm{M})$ and tet $(\mathrm{L})$ in Enterococcus faecalis," Veterinary Microbiology, vol. 139, no. 3-4, pp. 386-392, 2009.

[41] S. Pakpour, S. Jabaji, and M. R. Chénier, "Frequency of antibiotic resistance in a swine facility 2.5 years after a Ban on antibiotics," Microbial Ecology, vol. 63, no. 1, pp. 41-50, 2012.

[42] K. G. Byrne-Bailey, W. H. Gaze, P. A. Kay, A. B. A. Boxall, P. M. Hawkey, and E. M. H. Wellington, "Prevalence of sulfonamide resistance genes in bacterial isolates from manured agricultural soils and pig slurry in the United Kingdom," Antimicrobial Agents and Chemotherapy, vol. 53, no. 2, pp. 696-702, 2009.

[43] M. Kyselková, J. Jirout, A. Chroňáková et al., "Cow excrements enhance the occurrence of tetracycline resistance genes in soil regardless of their oxytetracycline content," Chemosphere, vol. 93, no. 10, pp. 2413-2418, 2013.

[44] C. Kopmann, S. Jechalke, I. Rosendahl et al., "Abundance and transferability of antibiotic resistance as related to the fate of sulfadiazine in maize rhizosphere and bulk soil," FEMS Microbiology Ecology, vol. 83, no. 1, pp. 125-134, 2013.

[45] N. Peak, C. W. Knapp, R. K. Yang et al., "Abundance of six tetracycline resistance genes in wastewater lagoons at cattle feedlots with different antibiotic use strategies," Environmental Microbiology, vol. 9, no. 1, pp. 143-151, 2007.

[46] R. Pei, S.-C. Kim, K. H. Carlson, and A. Pruden, "Effect of river landscape on the sediment concentrations of antibiotics and corresponding antibiotic resistance genes (ARG)," Water Research, vol. 40, no. 12, pp. 2427-2435, 2006.

[47] C. W. McKinney, K. A. Loftin, M. T. Meyer, J. G. Davis, and A. Pruden, "Tet and sul antibiotic resistance genes in livestock lagoons of various operation type, configuration, and antibiotic occurrence," Environmental Science \& Technology, vol. 44, no. 16, pp. 6102-6109, 2010.

[48] L. Liu, C. Liu, J. Zheng et al., "Elimination of veterinary antibiotics and antibiotic resistance genes from swine wastewater in the vertical flow constructed wetlands," Chemosphere, vol. 91, no. 8, pp. 1088-1093, 2013.

[49] T. O. Rahube and C. K. Yost, "Characterization of a mobile and multiple resistance plasmid isolated from swine manure and its detection in soil after manure application," Journal of Applied Microbiology, vol. 112, no. 6, pp. 1123-1133, 2012.

[50] C. W. Knapp, J. Dolfing, P. A. I. Ehlert, and D. W. Graham, "Evidence of increasing antibiotic resistance gene abundances in archived soils since 1940," Environmental Science \& Technology, vol. 44, no. 2, pp. 580-587, 2010.

[51] N. Wang, X. Yang, S. Jiao, J. Zhang, B. Ye, and S. Gao, "Sulfonamide-resistant bacteria and their resistance genes in soils fertilized with manures from Jiangsu Province, Southeastern China," PLoS ONE, vol. 9, no. 11, Article ID el12626, 2014. 

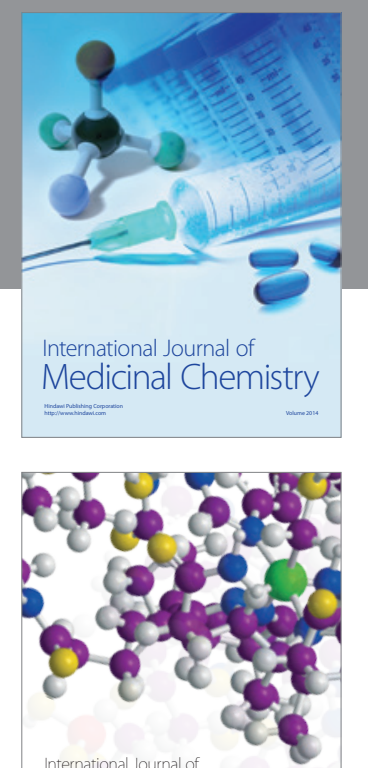

\section{Carbohydrate} Chemistry

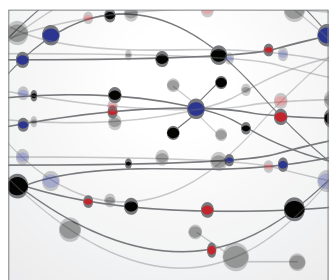

The Scientific World Journal
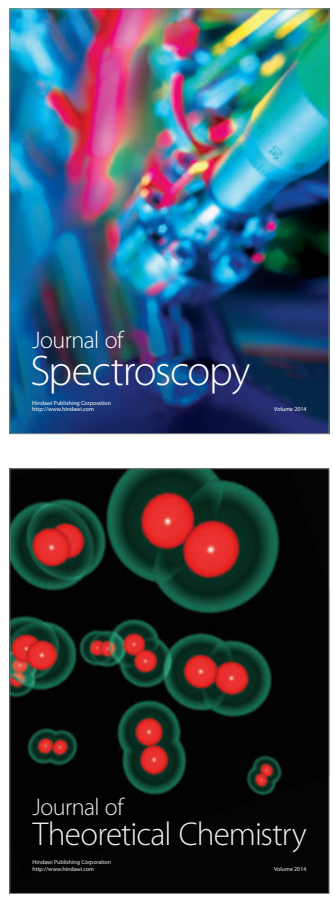
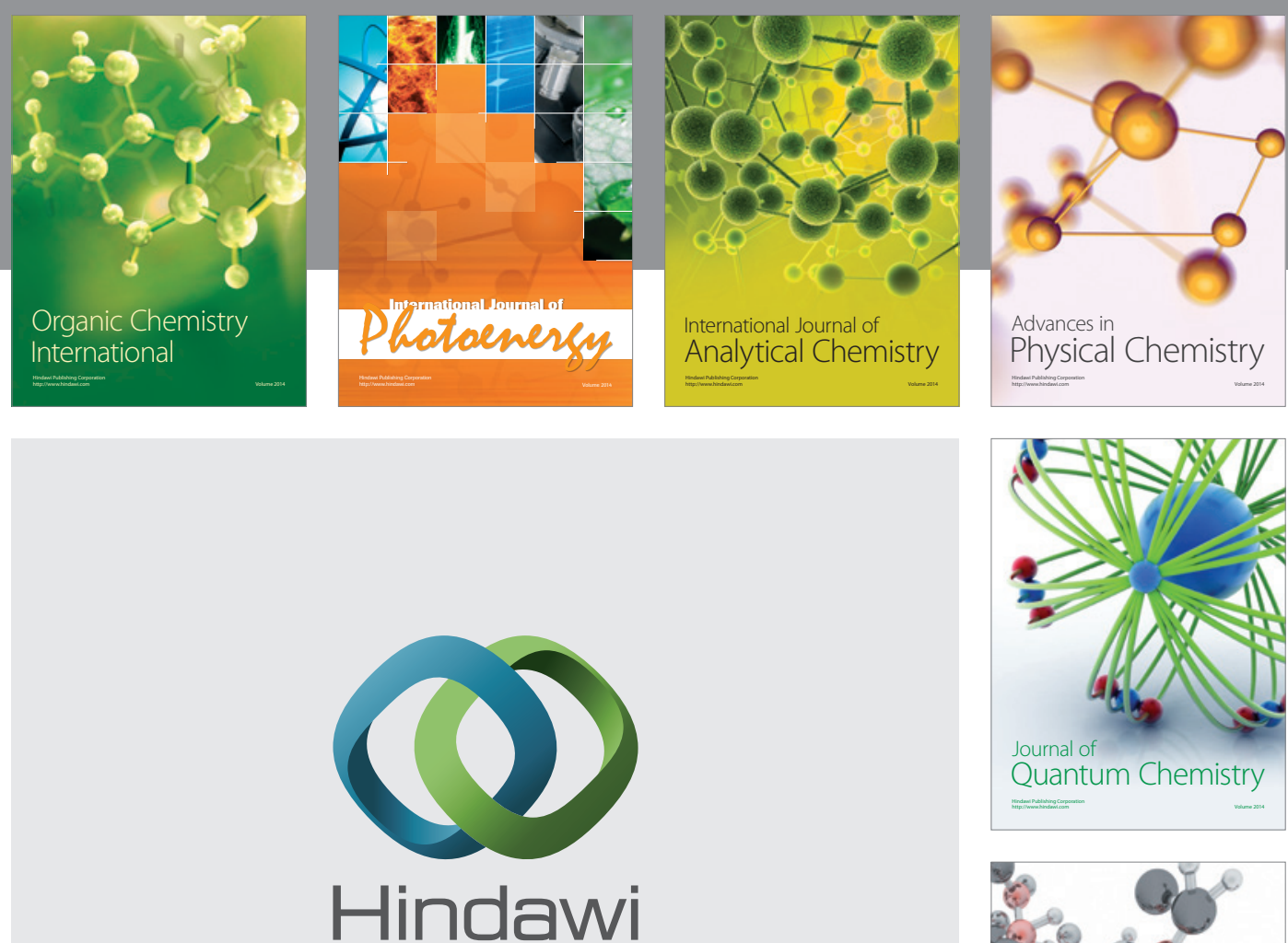

Submit your manuscripts at

http://www.hindawi.com

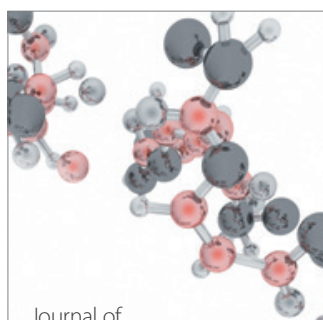

Analytical Methods

in Chemistry

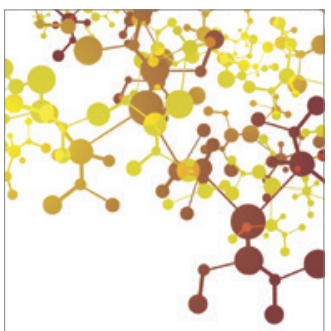

Journal of

Applied Chemistry

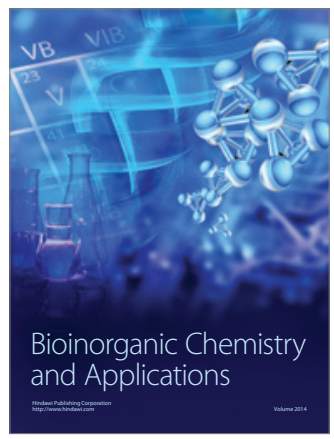

Inorganic Chemistry
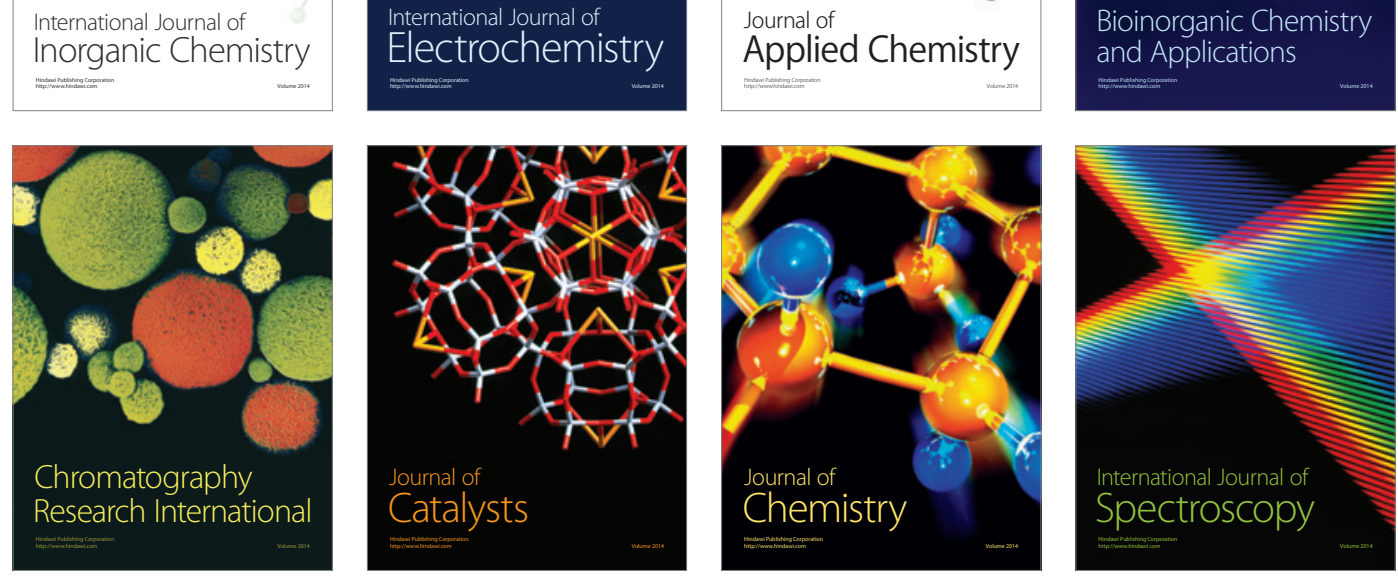